\section{Bring The Questions of Artificial Intelligence}

\section{S. Joshua Swamidass (D)}

https://doi.org/10.54739/q9qr

$T$ he Wall Street Journal published an article by me, "Evangelicals Take on Artificial Intelligence." This article responds to a theological statement on artificial intelligence (AI). About 70 theologians and pastors articulated their religious convictions, but I am much more interested in the questions.

AI is increasingly important in society at large, so we welcome new voices. Interest is high, because AI challenges our notions of what it means to be human. The possibility of artificial minds in the future is a mystery. Could something like Commander Data ever emerge? What would be the meaning of an artificial mind?

Regarding this particular statement on AI. Jordan Mantha, one of our scientists, summarizes my point well.

I think the danger you are pointing out, as I read your article, is that if we have a knee-jerk response before engaging with the science, we may end up with superficial theological responses that don't

\section{References}

https://peacefulscience.org/articles/wsj-ai-evangelicals/

https://erlc.com/resource-library/statements/artificial-intelligence-anevangelical-statement-of-principles

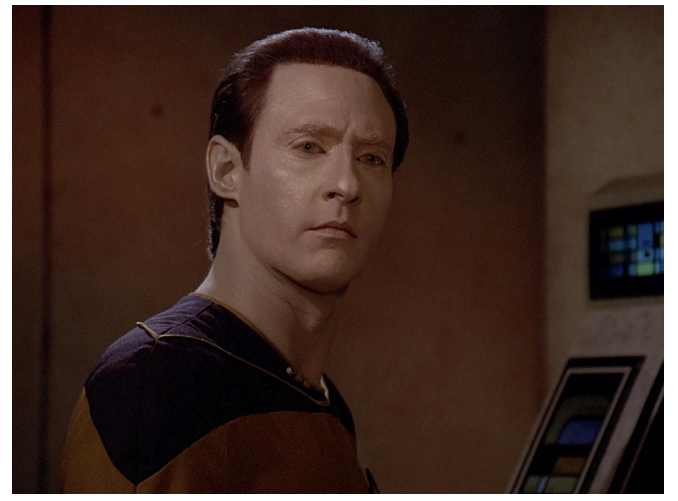

properly engage in the tougher questions that we really need thoughtful Christian voices involved in.

I think one of the struggles here is that it this was set up as "Christian theology" vs "materialistic science" and so theology becomes the "brakes" to slow the inevitable march of science towards a value-less and purely utilitarian society. What I see in a place like Peaceful Science is a group of diverse people who share a lot of common ground but approaches the grand questions differently. What if scientists, Christians, and especially Christians in science got together to share their ethical concerns, what the possibilities look like, and chart out a path forward?

Whoever you are, bring us your questions about AI. Join the conversation about its place in society in our current moment, or even about the meaning of artificial minds. This brings us back to the grand question, our focus here at Peaceful Science.

What does it mean to be human?

https://peacefulscience.org/ 